\title{
Photovoltaic properties and annealing effects of a low bandgap copolymer containing dithienothiophene and benzothiadiazole units
}

\author{
T. L. Wang ${ }^{1 *}$, Y. T. Shieh ${ }^{1}$, C. H. Yang ${ }^{1}$, T. H. Ho ${ }^{2}$, C. H. Chen ${ }^{3}$ \\ ${ }^{1}$ Department of Chemical and Materials Engineering, National University of Kaohsiung, 811 Kaohsiung, Taiwan, \\ Republic of China \\ ${ }^{2}$ Department of Chemical and Materials Engineering, National Kaohsiung University of Applied Sciences, 807 \\ Kaohsiung, Taiwan, Republic of China \\ ${ }^{3}$ Department of Electronic Engineering, Cheng Shiu University, 833 Kaohsiung, Taiwan, Republic of China
}

Received 13 June 2012; accepted in revised form 29 August 2012

\begin{abstract}
A conjugated alternating copolymer as the donor material of the active layer in polymer solar cells has been designed and synthesized via Stille coupling reaction. The alternating structure consisted of 3,5-didecanyldithieno[3,2b:2',3'-d]thiophene (DDTT) donor unit and 5,6-bis(tetradecyloxy)benzo-2,1,3-thiadiazole (BT) acceptor unit. Since both units have been attached pendant chains, the polymer was soluble in common organic solvents. UV-vis spectrum exhibited a broad absorption band in the range of $270-780 \mathrm{~nm}$ and a low bandgap of $1.83 \mathrm{eV}$. The highest occupied molecular orbital (HOMO) and lowest unoccupied molecular orbital (LUMO) energy levels of the polymer were estimated to be -5.10 and -3.27 eV, respectively. Based on the ITO/PEDOT:PSS/PDDTTBT:PCBM/Al device structure, the power conversion efficiency (PCE) under the illumination of AM $1.5\left(100 \mathrm{~mW} / \mathrm{cm}^{2}\right)$ was $0.127 \%$. The effects of annealing temperature $(50-$ $150^{\circ} \mathrm{C}$ ) for $30 \mathrm{~min}$ on the device performance were studied. It was found that PCE of $0.292 \%$ could be acquired under the annealing condition at $50^{\circ} \mathrm{C}$ for $30 \mathrm{~min}$. The improved device efficiency under the optimal condition was confirmed by the higher light harvest in UV-vis spectra, the enhanced quenching of photoluminescence (PL) emission, and the improved nanoscale morphology by atomic force microscopy (AFM) examination.
\end{abstract}

Keywords: nanomaterials, polymer solar cells, low bandgap, annealing

\section{Introduction}

Over the past decades, polymer solar cells (PSCs) based on conjugated polymers have attracted considerable attention because of their potential use for future cheap and renewable energy production [13]. In particular, the polymer solar cell has the advantage over all photovoltaic technologies that the possible manufacturing speed is very high and the thermal budget is low because no high temperatures are needed [4]. Efficient polymer-based solar cells utilize donor-electron acceptor (D-A) bulk heterojunction (BHJ) films as active layers $[1,2]$.
The donor is typically a kind of conjugated polymer, while the acceptor is generally a type of organic or inorganic molecule. The most exploited donor polymers is regioregular poly(3-hexylthiophene) (P3HT), while the acceptor materials are generally the fullerene derivatives such as $[6,6]-$ phenyl $\mathrm{C}_{61}$ butyric acid methyl ester (PCBM). A bulk heterojunction photovoltaic device combining regioregular $\mathrm{P} 3 \mathrm{HT}$ as the electron donor with functionalized fullerenes as the electron acceptor has demonstrated power conversion efficiencies (PCEs) up to $7 \%[5,6]$.

\footnotetext{
${ }^{*}$ Corresponding author, e-mail: tlwang@nuk.edu.tw

(C) BME-PT
} 
However, the performance of the photovoltaic cells with these conjugated polymers is considerably limited by their relatively large bandgaps, which result in the mismatch of the absorption spectrum of the active layer and the solar emission, especially in the red and near-infrared ranges. Therefore, the development of the low bandgap donor polymers is of crucial importance for increasing the efficiency. One of the most promising strategies to tailor the energy levels of conjugated polymer is the donoracceptor route because of the vast possibility in the unit combinations [7-11] Many D-A type copolymers have been used in PSCs to achieve PCEs above $5 \%$ with extensive device engineering efforts [7, 12-14].

For the D-A type copolymers, much research work has been devoted to using the fused thiophene family as the donor due to its stable quinoid form resulting in a low bandgap accompanied by good electrochemical stability [15-17]. Molecules containing fused-ring systems can make the polymer backbone more rigid and coplanar, therefore enhancing effective $\pi$-conjugation, lowering bandgap and extending absorption. Introduction of thienothiophene units tends to stabilize the quinoid structure in the polymer chain and thus enhances the planarity along the polymer backbone. The high power conversion efficiency can be attributed to the rigidity and planarity of the polymer backbone, leading to a high hole mobility of the copolymer. In the case of fused-ring systems, dithieno[3,2-b:2',3'-d]thiophene (DTT) is well known as an important building block due to its high mobility $[18,19]$. Recently, organic field-effect transistors (OFET) [20, 21] and PSCs [22, 23] containing dithieno[3,2-b:2', $3^{\prime}$-d] thiophene (DTT) building block in the D-A type copolymers have been reported.

Recently, 2,1,3-benzothiadiazole (BT) has been utilized to construct some n-type semiconducting polymers showing high electron mobility [24-26]. It has also been used as the acceptor unit in cooperation with varieties of electron-donating (D) units as low bandgap donors in bulk heterojunction polymer solar cells [23, 27-30]. High hole mobility and wide optical absorption band could be achieved for the D-A type BT-containing polymers. Hence, this category of polymer donors has been extensively studied and has shown outstanding photovoltaic performances.
Based on this vision, the copolymer consisting of alternating DTT and BT units, where DTT and BT are adopted as the donor and acceptor segments, should be a promising material for the active layer of solar cells. Recently, this copolymer has been prepared and explored in roll-to-roll coating experiments [31-33]. However, the acquired PCEs of photovoltaic devices based on this polymer are still low. It may be helpful to raise the PCE via the bandgap engineering strategy. Since only alkyloxy side chains were attached on the BT unit in this copolymer, the highest occupied molecular orbital (HOMO) and lowest unoccupied molecular orbital (LUMO) energy levels of the polymer may be modified if pendant chains are attached to both the donor and acceptor units . Herein, we have synthesized a new D-A type copolymer consisting of alternating DTT and BT units, where the DTT and BT unit has pendent alkyl chains and alkyloxy chains, respectively. The optoelectronic properties, PCE and the effect of thermal annealing of the fabricated PSCs were investigated.

\section{Experimental}

\subsection{Materials}

Tetrabromothiophene (Alfa Aesar, USA), undecanal (Alfa Aesar, USA), ethyl mercaptoacetate (Acros, Belgium), n-butyllithium (Acros, Belgium), lithium hydroxide (Alfa Aesar, USA), tin(II) chloride (Alfa Aesar, USA), sodium bichromate (Showa Chemical Co., Japan), potassium carbonate (Showa Chemical Co., Japan), triethylamine (Acros, Belgium), $\mathrm{N}$ thionylaniline (TCI, Japan), trimethyltin chloride (Acros, Belgium), bis(triphenylphosphine) palladium(II) dichloride (Alfa Aesar, USA), poly(3,4ethylenedioxythiophene)-poly(styrenesulfonate) (PEDOT:PSS, Aldrich, USA) and phenyl- $\mathrm{C}_{61^{-}}$ butyric acid methyl ester (PCBM, FEM Tech., Germany) were used as received. All other reagents were used as received.

\subsection{Synthesis}

The donor material, 3,5-didecanyldithieno[3,2$\left.\mathrm{b}: 2^{\prime}, 3^{\prime}-\mathrm{d}\right]$ thiophene (DDTT), was prepared according to a reported literature method [34]. The acceptor material, 5,6-bis(tetradecyloxy)benzo-2,1,3thiadiazole (BT) was prepared according to the published procedures [35]. The copolymer poly(3,5didecanyldithieno[3,2-b:2',3'-d] thiophene-2,6-diyl- 
alt-5,6-bis(tetradecyloxy)benzo-2,1,3-thiadiazole4,7-diyl) (PDDTTBT) was synthesized via Stille coupling reaction of the donor unit of 2,6-bistrimethylstannanyl-3,5-didecanyl dithieno[3,2-b: $2^{\prime}, 3^{\prime}$-d] thiophene with the acceptor unit of 4,7dibromo-5,6-bis(tetradecyloxy)benzo-2,1,3-thiadiazole.

\subsubsection{2,6-Bis-trimethylstannanyl $(3,5-$} didecanyldithieno[3,2-b:2'3'-d] thiophene)

To a solution of 3,5-didecanyldithieno[3,2-b:2',3'-d] thiophene $(1.12 \mathrm{mmol})$ in THF $(40 \mathrm{~mL})$ was added dropwise n-BuLi (2.5 mmol, $1.6 \mathrm{M}$ in hexane) at $-78^{\circ} \mathrm{C}$ under argon. The reaction was keep at $-78^{\circ} \mathrm{C}$ for $2 \mathrm{~h}$. Then trimethylchlorostannane $(2.5 \mathrm{mmol})$

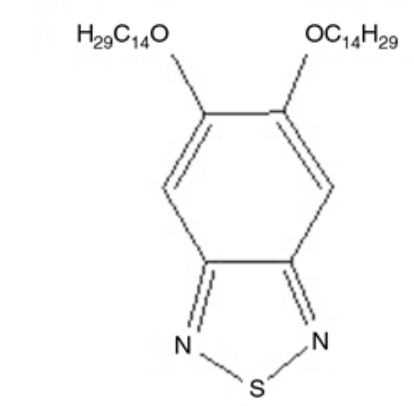

5,6-bis(tetradecyloxy)benzo-2,1,3-thiadiazole

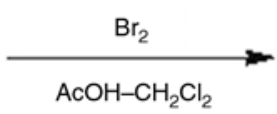<smiles>CCCc1csc2c1sc1c(C)csc12</smiles>

3,5-Didecanyldithieno[3,2-b:2'3'-d]thiophene

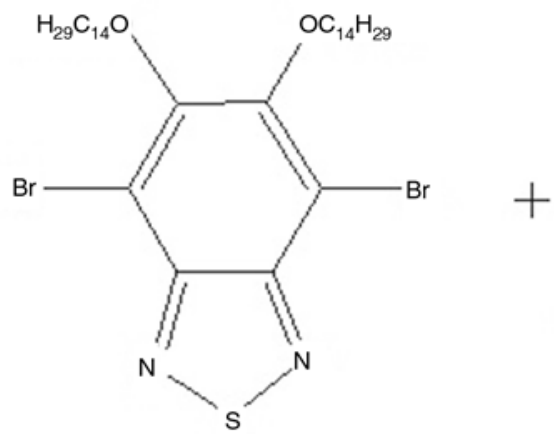

4,7-Dibromo-5,6-bis(tetradecyloxy)benzo-2,1,3-thiadiazole

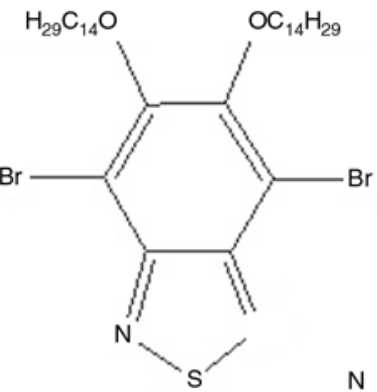

4,7-dibromo-5,6-bis(tetradecyloxy)benzo-2,1,3-thiadiazole

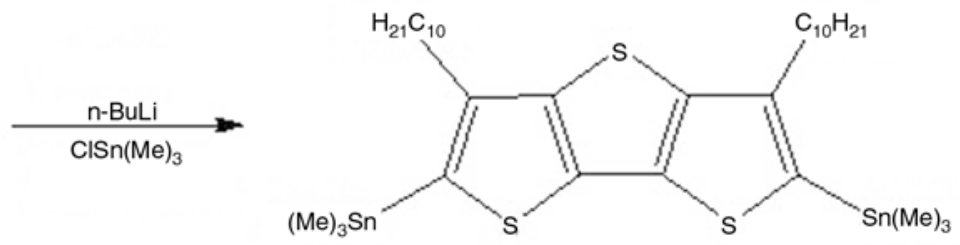

2,6-Bis-trimethylstannanyl(3,5-didecanyldithieno[3,2-b:2'3'-d]thiophene)

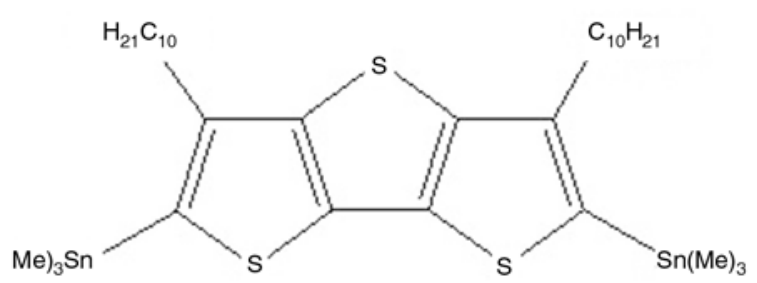

2,6-Bis-trimethylstannanyl(3,5-didecanyldithieno[3,2-b:2'3'-d]thiophene)

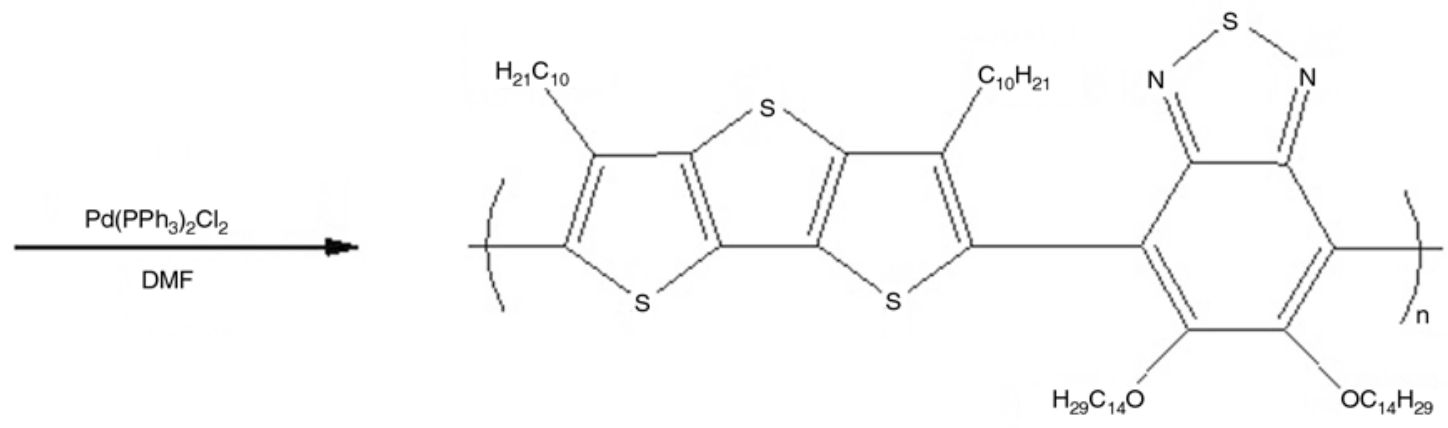

PDDTTBT

Figure 1. Synthesis of PDDTTBT copolymer 
was added. The reaction mixture was allowed to warm to room temperature and react for $10 \mathrm{~h}$, and it was poured into water $(100 \mathrm{~mL})$. The crude compound was extracted with dichloromethane three times. The combined organic layers were dried over anhydrous $\mathrm{MgSO}_{4}$ and evaporated to dryness. The residue was chromatographically purified on silica gel eluting with n-hexane/triethylamine (10:1, v:v) to afford the products as a viscous brown oil, which were used for the following reactions without further purification. The synthetic route is shown in Figure 1. Yield: $41 \% .{ }^{1} \mathrm{H}$ NMR $\left(500 \mathrm{MHz}, \mathrm{CDCl}_{3}\right.$, $\delta$ ppm): $2.62(\mathrm{t}, 4 \mathrm{H}), 1.83(\mathrm{~m}, 4 \mathrm{H}), 1.25$ (m, 28H), $0.88(\mathrm{t}, 6 \mathrm{H}), 0.27\left(\mathrm{~s}, 18 \mathrm{H}, \mathrm{Sn}-\mathrm{CH}_{3}\right)$.

\subsubsection{4,7-Dibromo-5,6-bis(tetradecyloxy)benzo- 2,1,3-thiadiazole}

5,6-Bis(tetradecyloxy)benzo-2,1,3-thiadiazole (2.5 mmol) was dissolved in $70 \mathrm{~mL}$ of dichloromethane under argon atmosphere. Excess $\mathrm{Br}_{2}$ (7.5 mmol) was dissolved in $30 \mathrm{~mL}$ of acetic acid and added into the solution. The reaction was stirred in the dark at room temperature for $48 \mathrm{~h}$ and then poured into water $(100 \mathrm{~mL})$. The organic layer was separated and the aqueous layer was extracted with dichloromethane. The combined organic layer was sequentially washed with de-ionized water, aq. $\mathrm{NaHCO}_{3}$ and aq. $\mathrm{Na}_{2} \mathrm{SO}_{3}$ twice. The combined organic layers were dried over anhydrous $\mathrm{MgSO}_{4}$ and evaporated to dryness. The crude product was recrystallized from ethanol to give white needlelike crystals. The synthetic route is shown in Scheme 1. Yield: $82 \% .{ }^{1} \mathrm{H}$ NMR (500 MHz, $\mathrm{CDCl}_{3}$, $\delta \mathrm{ppm}): 4.15(\mathrm{t}, 4 \mathrm{H}), 1.87(\mathrm{~m}, 4 \mathrm{H}), 1.57(\mathrm{~m}, 4 \mathrm{H})$, $1.37-1.26(\mathrm{~m}, 40 \mathrm{H}), 0.88(\mathrm{t}, 6 \mathrm{H})$.

\subsubsection{Synthesis of D-A type copolymer (PDDTTBT)}

In a $100 \mathrm{~mL}$ flask, the two monomers $(1 \mathrm{mmol}$ of each), 2,6-bis-trimethylstannanyl(3,5-didecanyldithieno[3,2-b:2'3'-d]thiophene) and 4,7-dibromo5,6-bis(tetradecyloxy)benzo-2,1,3-thiadiazole were dissolved in $40 \mathrm{~mL}$ of dry DMF and then flashed by argon for $10 \mathrm{~min}$. Following that, $0.02 \mathrm{mmol}$ of $\mathrm{Pd}\left(\mathrm{PPh}_{3}\right)_{2} \mathrm{Cl}_{2}$ was added, and the reactant was purged by argon for another $20 \mathrm{~min}$. The reaction mixture was then heated at $120^{\circ} \mathrm{C}$ for $48 \mathrm{~h}$ under the protection of argon. The sticky, deep gray solution was cooled and poured into $100 \mathrm{~mL}$ of methanol, where the crude polymer was precipitated and col- lected as dark brown powder, which was then subjected to Soxhlet extraction with methanol, hexane, and THF. The polymer was recovered from the THF fraction by rotary evaporation. The synthetic route is shown in Figure 1. Yield: 43\%. ${ }^{1} \mathrm{H}$ NMR $\left(500 \mathrm{MHz}, \mathrm{CDCl}_{3}, \delta \mathrm{ppm}\right): 4.15(\mathrm{t}, 4 \mathrm{H}), 2.62(\mathrm{t}$, $4 \mathrm{H}), 1.76(\mathrm{~m}, 4 \mathrm{H}), 1.56(\mathrm{~m}, 4 \mathrm{H}), 1.30(\mathrm{~m}, 4 \mathrm{H}), 1.27$ $(\mathrm{m}, 68 \mathrm{H}), 0.88(\mathrm{t}, 12 \mathrm{H})$. Anal. Calcd for $\left(\mathrm{C}_{62} \mathrm{H}_{100} \mathrm{~N}_{2} \mathrm{O}_{2} \mathrm{~S}_{4}\right)_{\mathrm{n}}: \mathrm{C}, 72.03 ; \mathrm{H}, 9.75 ; \mathrm{N}, 2.71$. Found: C, 73.42; H, 9.24; N, 3.03. GPC (THF): $\overline{M_{\mathrm{n}}}=6800 \mathrm{~g} / \mathrm{mol}, \overline{M_{\mathrm{w}}}=8200 \mathrm{~g} / \mathrm{mol}$, PDI $=1.21$.

\subsection{Device fabrication and characterization}

The device structure of the polymer photovoltaic cells in this study is ITO/PEDOT:PSS/PDDTTBT: $\mathrm{PCBM} / \mathrm{Al}$. PDDTTBT acts as the p-type donor polymer and PCBM as the n-type acceptor in the active layer. Before device fabrication, the glass substrates coated with indium tin oxide (ITO) were first cleaned by ultrasonic treatment in acetone, detergent, deionized water, methanol and isopropyl alcohol sequentially. The ITO surface was spin coated with ca. $80 \mathrm{~nm}$ layer of poly(3,4-ethylene dioxythiophene): poly(styrene) (PEDOT:PSS) in the nitrogen-filled glove-box. The substrate was dried for $10 \mathrm{~min}$ at $150^{\circ} \mathrm{C}$ and then continued to spin coating the active layer. The PDDTTBT: PCBM blend solutions were prepared with 1:1 weight ratio $(10 \mathrm{mg} / \mathrm{mL}$ PDDTTBT) in 1,2-dichlorobenzene (DCB) as the active layer. This solution blend was spin-cast onto the PEDOT:PSS layer at $800 \mathrm{rpm}$ for $30 \mathrm{~s}$. The obtained thickness for the blend film of PDDTTBT:PCBM was ca. $110 \mathrm{~nm}$. The devices were completed by evaporation of metal electrodes $\mathrm{Al}$ with area of $6 \mathrm{~mm}^{2}$ defined by masks.

The films of active layers were annealed directly on top of a hot plate in the glove box, and the temperature is monitored by using a thermocouple touching the top of the substrates. After removal from the hotplate, the substrates are immediately put onto a metal plate at the room temperature. Ultraviolet-visible (UV-vis) spectroscopic analysis was conducted on a Perkin-Elmer Lambda 35 UV-vis spectrophotometer. Photoluminescence (PL) spectrum was recorded on a Hitachi F-7000 fluorescence spectrophotometer. After removing Al electrode, the film topography images of active layers were recorded with a Digital Instruments Dimension 3100 atomic force microscope (AFM) in tapping mode under ambient conditions. The $J-V$ curves were measured 
using a Keithley 2400 source meter, under illumination from a solar simulator. The intensity of solar simulator was set with a primary reference cell and a spectral correction factor to give the performance under the AM $1.5\left(100 \mathrm{~mW} / \mathrm{cm}^{2}\right)$ global reference spectrum (IEC 60904-9). External quantum efficiency (EQE) measurements were detected with a QE-3000 (Titan Electro-Optics Co., Ltd.) lock-in amplifier under monochromatic illumination. Calibration of the incident light was performed with a monocrystalline silicon diode.

\section{Results and discussion}

\subsection{Synthesis and characterization of the polymer}

In this study, the D-A type copolymer consists of 3,5-didecanyldithieno[3,2-b:2',3'-d]thiophene (DDTT) and 2,1,3-benzothiadiazole (BT) because 2,1,3benzothiadiazole (BT) is an electron-accepting heterocycle showing high electron mobility and DDTT is linearly symmetrical and coplanar thienothiophene unit. It is expected that wide sunlight absorption band and high power conversion efficiency could be achieved for the D-A type copolymer using DDTT as the donor and BT as the acceptor.

The synthetic route toward the polymer is outlined in Figure 1. The copolymer PDDTTBT was synthesized via Stille coupling reaction of the donor unit of 2,6-bis-trimethylstannanyl(3,5-didecanyldithieno [3,2-b:2'3'-d]thiophene) with the acceptor unit of 4,7-dibromo-5,6-bis(tetradecyloxy)benzo-2,1,3-thiadiazole. With the attachment of long alkyl and long alkyoxyl side chains on the donor and acceptor unit respectively, the bandgap of the copolymer could be fine tuned and the solubility in organic phases increases. The structures of both monomers and

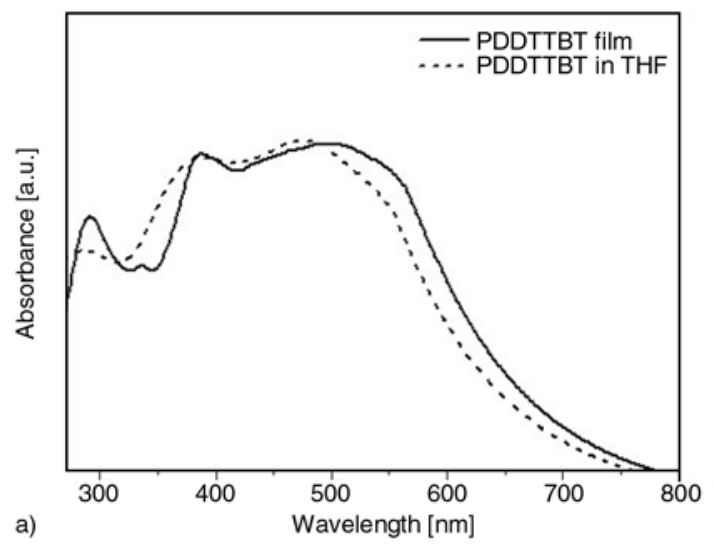

copolymer were confirmed by ${ }^{1} \mathrm{H}$ NMR and elemental analysis. The polymer is well dissolved in common organic solvents such as chloroform, 1,2dichlorobenzene, THF, and toluene. Molecular weight of the polymer determined by gel permeation chromatography showed a low $\overline{M_{\mathrm{n}}}$ value of 6800 , which might be due to the steric hindrance of both 3,5-dialkyl and 5,6-dialkyoxyl substituent on the polymer backbone. Compared to the copolymer reported in a previous article [33], which has a similar structure without pendent alkyl chains on the donor (dithienothiophene) unit, the PDDTTBT polymer exhibited a lower glass transition temperature $\left(T_{\mathrm{g}}\right)$ of $72^{\circ} \mathrm{C}$ due to the attachment of alkyl side chains on the donor unit.

\subsection{Optical properties}

Figure $2 \mathrm{a}$ shows the absorption spectra of the PDDTTBT copolymer in dilute THF solution and in thin solid film. The optical absorption threshold at $707 \mathrm{~nm}$ from the spectrum of the film corresponds to the bandgap $\left(E_{\mathrm{g}}\right)$ of the PDDTTBT copolymer. Hence, the estimated optical bandgap is $1.75 \mathrm{eV}$. To obtain a more accurate optical band gap of PDDTTBT, the fundamental equation $\alpha h v=B(h v-$ $\left.E_{\text {opt }}\right)^{\mathrm{n}}$ developed in Tauc relation [36] was used. The optical bandgap calculated by this equation is $1.83 \mathrm{eV}$, smaller than that $(1.9-2.0 \mathrm{eV})$ of widely used regioregular poly(3-hexylthiophene) (P3HT), as shown in Figure 2b. In comparison with the polymer which has a similar structure without alkoxy chains on the acceptor (benzothiadiazole) unit [23], the PDDTTBT copolymer exhibits a broader absorption band and lower bandgap. On the other hand, from our previous report [33], the bandgap of the similar copolymer without pendent alkyl side chains

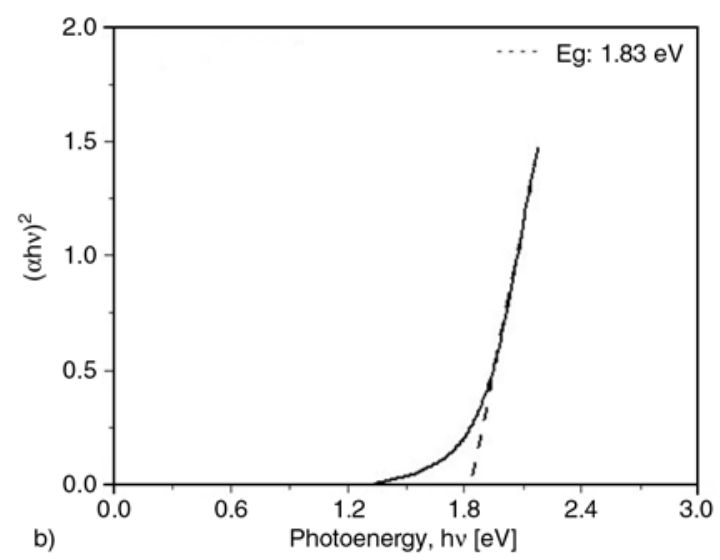

Figure 2. (a) UV-vis absorption spectra of PDDTTBT in dilute THF solution and thin film, (b) plot of $(\alpha h v)^{2}$ vs. $h v$ for PDDTTBT film 
on the donor (DTT) unit is $1.76 \mathrm{eV}$ (via absorption threshold) or $1.83 \mathrm{eV}$ (via Tauc relation). It is obvious that the bandgaps of both copolymers are almost the same. Therefore, to finetune the bandgap with the attachment of pendant chains on the donor unit seems no significant influence on the value of bandgap in the present case. However, it doesn't mean that the HOMO and LUMO values of both copolymers will be the same, as we will discuss in section 3.3.

As seen from Figure 2a, the UV-vis absorption spectrum of the copolymer in thin solid film exhibited three absorption peaks positioned at about 291, 385 and $505 \mathrm{~nm}$, respectively. The peaks at 291 and $385 \mathrm{~nm}$ are probably due to the $\pi-\pi^{*}$ transition of the dithienothiophene moiety [37], while the peak in the visible region is assigned to the intramolecular charge transfer (ICT) between the donor and the acceptor [23, 38]. Similarly, the absorption spectrum of PDDTTBT in dilute THF also shows three peaks. The three absorptions in solid state show significant red-shifts compared to those in solution, indicating more efficient $\pi$-stacking and stronger intermolecular interactions in the solid state. In particular, the broadened absorption spectrum ranging from 270 to $780 \mathrm{~nm}$ indicates a low bandgap polymer has obtained, as evident from the $E_{\mathrm{g}}$ of PDDTTBT. It is apparent that the ICT interaction between donor and acceptor moieties in $\mathrm{D}-\mathrm{A}$ copolymers is a practical approach to lower the bandgap and broaden the absorption bands across the entire visible wavelength region of conjugated polymers. Hence, our successful synthesis of a low bandgap D-A type copolymer is further confirmed.

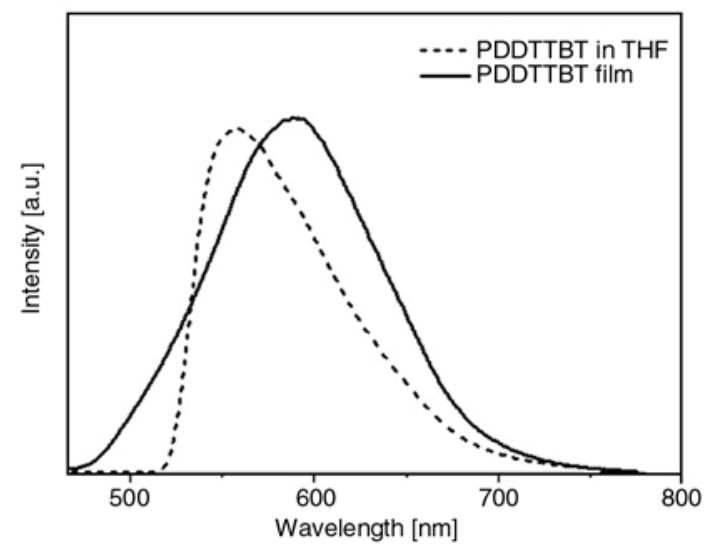

Figure 3. Photoluminescence spectra of PDDTTBT in dilute THF solution and thin film with excitation at $400 \mathrm{~nm}$
The photoluminescence (PL) emission spectra of PDDTTBT in dilute THF solution and thin film are shown in Figure 3. Both the fluorescence spectra exhibit the vibronic structure with a maximum at 557 and $589 \mathrm{~nm}$, respectively. As seen from the figure, both spectra show only one emission peak, indicating that an effective energy transfer from the DDTT segments to the BT unit occurs. The redshift in the spectrum of the PDDTTBT film is probably due to the lowering of bandgap of copolymer by more efficient $\pi$-stacking in the solid state.

\subsection{Electrochemical properties}

Cyclic voltammetry $(\mathrm{CV})$ is a preliminary characterization technique to determine the redox properties of organic and polymeric materials. The HOMO energy level can be calculated from the onset oxidation potential $\left[E_{\mathrm{ox}}(\mathrm{onset})\right]$ based on the reference energy level of ferrocene ( $4.8 \mathrm{eV}$ below the vacuum level, which is defined as zero) according to Equation (1). The LUMO level can be obtained from Equation (2) based on the $E_{\mathrm{g}}$ from Figure 2. $E_{\mathrm{FC}}$ is the potential of the internal standard, the ferrocene/ ferrocenium $\left(\mathrm{Fc} / \mathrm{Fc}^{+}\right)$redox couple.

$\mathrm{HOMO}=-\left[E_{\mathrm{ox}}\right.$ (onset) $\left.-E_{\mathrm{FC}}+4.8\right] \mathrm{eV}$

$\mathrm{LUMO}=\mathrm{HOMO}+E_{\mathrm{g}}$

As seen in Figure 4, the $E_{\text {ox }}$ (onset) for PDDTTBT has been determined as $0.35 \mathrm{~V}$ vs. $\mathrm{Ag} / \mathrm{Ag}^{+} . E_{\mathrm{FC}}$ is $0.05 \mathrm{~V}$ vs. $\mathrm{Ag} / \mathrm{Ag}^{+}$. Hence, the HOMO energy for PDDTTBT has been evaluated to be $-5.10 \mathrm{eV}$ and the LUMO level determined from Equation (2) is

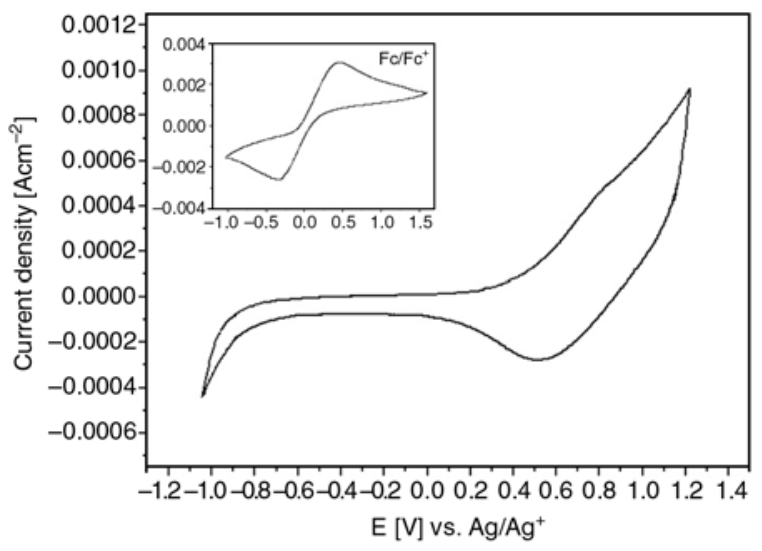

Figure 4. Cyclic voltammograms of PDDTTBT film on an ITO substrate in $\mathrm{CH}_{3} \mathrm{CN} / \mathrm{AcOH}(\mathrm{V} / \mathrm{V}=7 / 1)$ containing $0.1 \mathrm{M}$ tetrabutylammonium perchlorate at a scan rate of $50 \mathrm{mV} \cdot \mathrm{s}^{-1}$ 


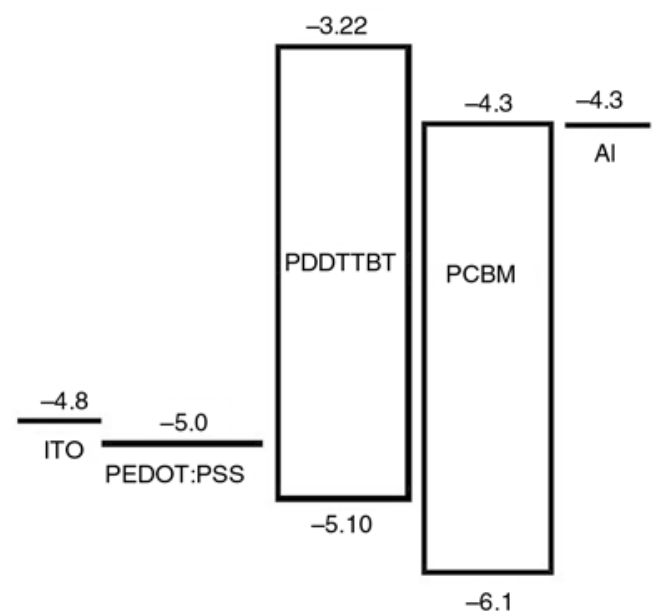

Figure 5. Energy level diagram of the components in the polymer solar cell

$-3.27 \mathrm{eV}$. Since incorporation of electron-donating substituents onto the aromatic unit will raise the HOMO energy, the PDDTTBT polymer thus has a higher HOMO level than that of the similar structure without alkoxy groups on the BT unit [23]. In a similar manner, compared to the similar structure without pendant chains on the DTT unit [33], the HOMO level increases ca. $0.05 \mathrm{eV}$ due to two electron donating alkyl chains were attached onto the fused thiophene ring. Figure 5 shows the schematic diagram representing the potential metrically determined HOMO and LUMO energy of PDDTTBT and PCBM relative to the work function of the electrodes. From the energy level diagram, although the $\Delta E_{\mathrm{LUMO}}$ between the LUMOs of donor (PDDTTBT) and acceptor (PCBM) is large enough to meet the minimum energy offset $(0.3 \mathrm{eV})$ for efficient charge separation, the increase of HOMO level in donor material may produce a detrimental reduction of $V_{\text {oc }}$, as can be seen in the $J-V$ measurements.

\subsection{Photovoltaic properties}

The bulk heterojunction solar cells based on PDDTTBT in combination of PCBM has been prepared and investigated. The employed device structure was ITO/PEDOT:PSS/PDDTTBT:PCBM/Al. The blend solutions (in DCB) of PDDTTBT:PCBM were prepared with $1: 1$ weight ratio as the active layer. The photovoltaic performance of the device for the blend film cast at room temperature (RT) was measured under illumination from solar simulator at $100 \mathrm{~mW} / \mathrm{cm}^{2}$ light intensity. The corresponding open-circuit voltage $\left(V_{\text {oc }}\right)$, short-circuit current $\left(J_{\text {sc }}\right)$, fill factor $(\mathrm{FF})$, and power conversion efficiency $(\mathrm{PCE}, \eta)$ are listed in Table 1 . The power
Table 1. Photovoltaic characteristics of devices under different annealing temperatures for $30 \mathrm{~min}$

\begin{tabular}{|l|r|r|r|r|r|r|}
\hline & \multicolumn{1}{|c|}{$\mathbf{R T}$} & $\mathbf{5 0}^{\circ} \mathbf{C}$ & $\mathbf{7 5}^{\circ} \mathbf{C}$ & $\mathbf{1 0 0}^{\circ} \mathbf{C}$ & $\mathbf{1 2 5}^{\circ} \mathbf{C}$ & $\mathbf{1 5 0}^{\circ} \mathbf{C}$ \\
\hline$V_{\text {oc }}[\mathrm{V}]$ & 0.284 & 0.451 & 0.581 & 0.544 & 0.433 & 0.475 \\
\hline$J_{\text {sc }}\left[\mathrm{mA} / \mathrm{cm}^{2}\right]$ & 1.512 & 1.933 & 1.361 & 1.123 & 1.726 & 1.004 \\
\hline FF $[\%]$ & 29.510 & 33.530 & 32.070 & 37.310 & 35.420 & 32.610 \\
\hline$\eta[\%]$ & 0.127 & 0.292 & 0.254 & 0.228 & 0.265 & 0.155 \\
\hline
\end{tabular}

conversion efficiency of solar cell using the as-prepared blend film as the active layer is $0.127 \%$. This value is only a little higher than that $(0.113 \%)$ of the similar structure without pendant chains on the DTT unit [33]. As mentioned above, due to the increase of HOMO level in PDDTTBT as compared with that of similar structure [33], a $0.032 \mathrm{~V}$ decrease $(0.284 \mathrm{~V}$ vs. $0.316 \mathrm{~V})$ of $V_{\text {oc }}$ produced. Therefore, although both Jsc and FF increased, only a little improvement of PCE was achieved. However, the values of both $J_{\mathrm{sc}}$ and FF are still low compared to those of high performance PSCs. The low $J_{\text {sc }}$ may be attributed to the high recombination rate of charge carriers, whereas the low $V_{\text {oc }}$ resulted from the high HOMO level of PDDTTBT. Regarding the low FF, it is usually caused by shunt resistance, series resistance, and film-forming properties, etc. Consequently, the poor performance of the device may be a result of the non-optimized morphology of the blend film, the poor technique for fabricating the active layer and the device architecture, the nature of the donor material, the fabrication equipments, etc.

\subsection{Effect of thermal annealing on optical properties}

The effect of annealing temperature on the UV-vis absorption spectra for the thin films of PDDTTBT:PCBM (1:1 weight ratio) spun cast on quartz substrates is shown in Figure 6. These films were annealed under nitrogen atmosphere inside the glove box at atmospheric pressure. The annealing time was kept 30 min for all of the annealing temperatures. After annealing at different temperatures, the blend film exhibited distinct intensity changes and shifts of the absorption bands compared with that of untreated PDDTTBT film. For the blend film annealed at $50^{\circ} \mathrm{C}$, the spectrum shows a significant increase in intensity for all three absorption bands of PDDTTBT copolymer, especially for the peak at $380 \mathrm{~nm}$. The two bands at lower wavelengths are attributed to the $\pi-\pi^{*}$ transition of DDTT segments, whereas the last band is due to ICT interaction as 


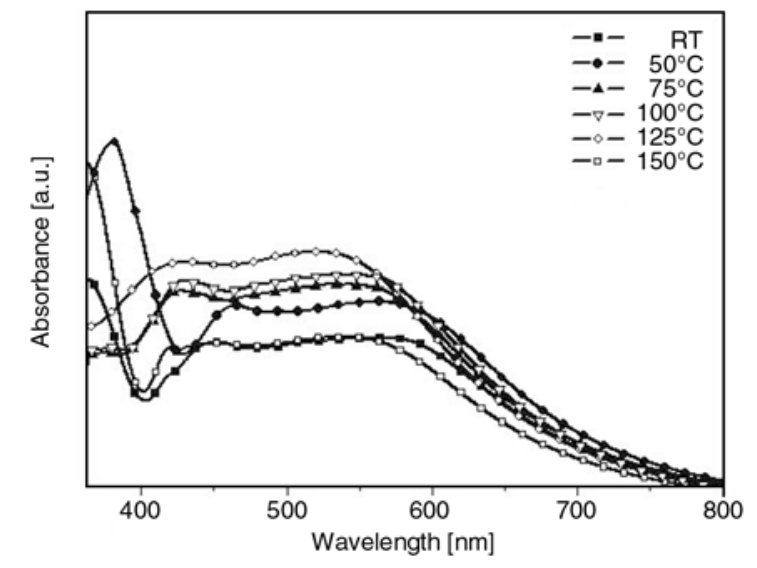

Figure 6. UV-vis absorption spectra of PDDTTBT:PCBM blend films after annealing at different temperatures for $30 \mathrm{~min}$

stated above. An increase in the absorption intensity after annealing suggests an increased packing of chains in the PDDTTBT domains, indicating the more ordered structure of PDDTTBT. The redshifts for the three bands imply that the conjugation length in PDDTTBT was enhanced by the heat treatment.

At annealing temperature of $75^{\circ} \mathrm{C}$, although the intensities of last two bands increase, the first peak disappears accompanying with a distinctive blueshift of the entire absorption band. The films heattreated at 100 and $125^{\circ} \mathrm{C}$ show similar behaviors. Further increasing the annealing temperature to $150^{\circ} \mathrm{C}$, however, results in a dramatic decrease in the intensities of last two bands while the first peak reappears in the vicinity of $362 \mathrm{~nm}$. The irregular changes in intensity and wavelength for the absorption bands with the annealing temperature may be associated with the molecular structure of the D-A type copolymer due to both donor and acceptor segments possessing pendent side chains. When the film annealed at $50^{\circ} \mathrm{C}$, the intermolecular packing of both fused-thiophene ring and BT unit could be accommodated by the decrease in the steric hindrance of the pendent side chains because of their easier movements than the rigid polymer backbone. Hence, the total absorption in the entire range is comparatively larger than other annealing temperatures. However, when the annealing temperature was raised to $75^{\circ} \mathrm{C}$ (above the $T_{\mathrm{g}}$ of PDDTTBT), the rigid polymer backbone also became mobile accompanying with a development of a new packing state and thus rendering a different absorption pattern. In this case, side chain ordering may decrease while the main chain planarity is enhanced. This may result in a decrease of intermolecular packing because of the steric hindrance of more mobile side chains and an increase of ICT interaction due to more planar structure of polymer backbone. Therefore, the absorption peak at $380 \mathrm{~nm}$ due to the $\pi-\pi^{*}$ transition of the dithienothiophene moiety disappears whereas the absorption at $412-580 \mathrm{~nm}$ increases. The similar absorption behavior with increasing absorption intensity was observed for the film annealed at 100 and $125^{\circ} \mathrm{C}$, indicating that the ICT interaction increased with increasing annealing temperature. For the sample annealing at $150^{\circ} \mathrm{C}$, both side chains and main chains of the PDDTTBT molecules could move simultaneously, leading to disordered packing state similar to that of untreated PDDTTBT film. Similar spectrum to that of the untreated PDDTTBT film was thus observed. As a result, the sample annealed at 50 or $125^{\circ} \mathrm{C}$ could provide optimal optoelectronic properties for PDDTTBT and PCBM blend films, as seen in Table 1.

The PL spectra for blend films annealed at different temperatures are shown in Figure 7. The PL intensity increases with the increase of photogenerated excitons that do not take part in charge separation. Hence, the phenomenon of PL quenching can be attributed to the effective charge transfer in the interfacial region of donor-acceptor junction. Normally, PL quenching increases with the increase of interfacial area between donor and acceptor materials in the active layer. Furthermore, the higher mobility of donor material after thermal annealing may increase the $\mu_{\mathrm{h}} / \mu_{\mathrm{e}}$ ratio and reduce the mobility mismatch between hole and electron transport and thus enhance the charge separation in the active layer.

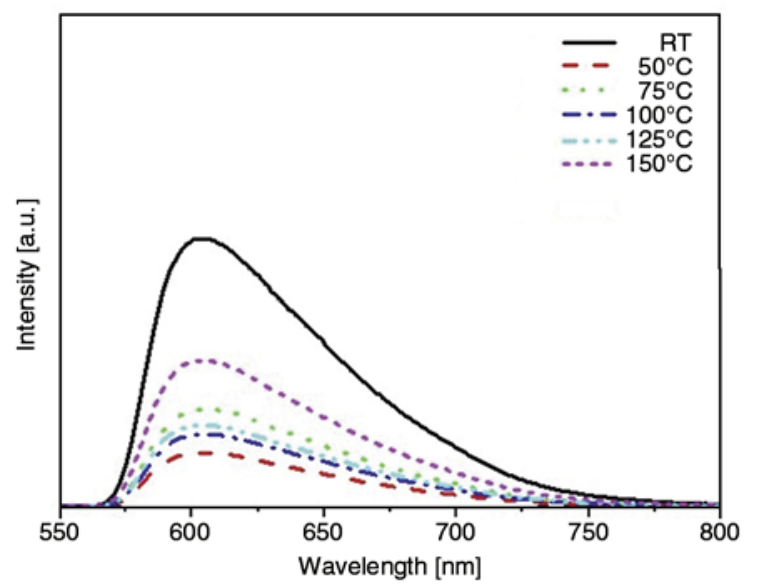

Figure 7. Photoluminescence spectra of PDDTTBT:PCBM blend films after annealing at different temperatures for $30 \mathrm{~min}$ with excitation at $375 \mathrm{~nm}$ 


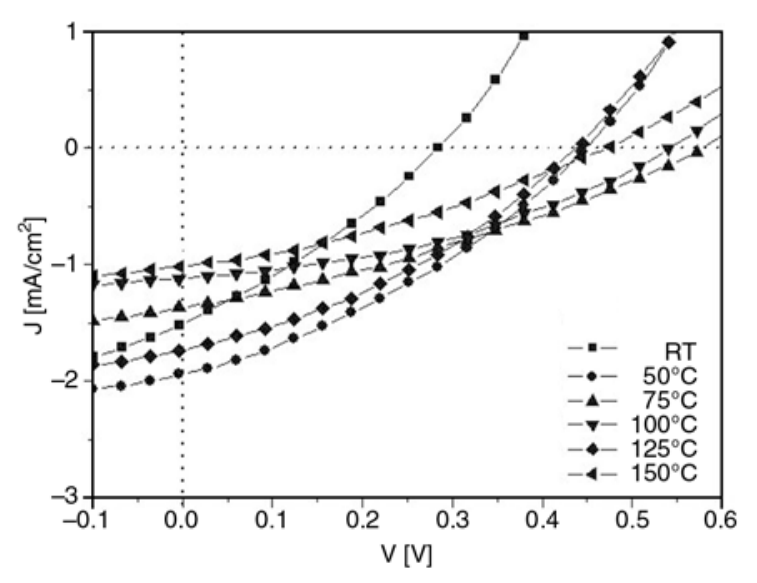

Figure 8. J-V characteristics of devices under AM 1.5 simulated solar illumination at an intensity of $100 \mathrm{~mW} / \mathrm{cm}^{2}$ after annealing at different temperatures for $30 \mathrm{~min}$

Therefore, if the charge mobility of the PDDTTBT polymer is improved due to annealing treatment and more ordered packing, the quenching effect will be enhanced. PL quenching provides direct evidence for exciton dissociation, and thus efficient PL quenching is necessary to obtain efficient organic solar cells. As shown in the Figure 6, it seems that the PL intensity decreases with the increase of UVvis intensity. The PL intensity shows a minimum at thermal annealing of $50^{\circ} \mathrm{C}$. This significant reduction in the PL intensity is attributed to efficient photoinduced charge separation between electron-donating (PDDTTBT) and electron-accepting (PCBM) molecules. This may be attributed to the higher charge carrier mobility or higher interfacial area between D-A molecules compared with those of other annealing temperatures. Hence, the highest power conversion efficiency $(0.292 \%)$ has been achieved by this blend film as shown in Figure 8 and Table 1.

However, this does not necessarily mean that the stronger the PL quenching, the better the performance of the solar cells, as shown in the curves for the annealing temperature at 75 and $100^{\circ} \mathrm{C}$. Although the PL intensity of the blend film annealed at $125^{\circ} \mathrm{C}$ is a little higher in comparison with that of the film annealed at $100^{\circ} \mathrm{C}$, the power conversion efficiency for the film annealed at $125^{\circ} \mathrm{C}$ is the second best as shown in Figure 8 and Table 1. As we stated in a previous study [33], it is probable that (1) the increase of optical absorption in the visible light region, (2) he improved charge carrier mobility in both donor and acceptor phases after thermal annealing, and (3) the increased interfacial area between the donor and acceptor phases, offsets the former effect (PL quenching) and results in an overall improvement in device performance. Moreover, as we will discuss in the following part, it seems that the highervalue ofroughness and higher degree of nanoscale phase separation in the blend film annealed at $50^{\circ} \mathrm{C}$ enhance the transport rate of charge carriers to the metal electrode and reduce the charge recombination of the excitons.

\subsection{Effect of thermal annealing on phase morphology}

Since the morphology of the heterojunction plays an important role on the performance of polymer solar cells, we studied the topography of blend films of PDDTTBT:PCBM $(1: 1, w / w)$ by AFM. Although the AFM images of film surfaces at different annealing temperatures have been taken, for the sake of simplicity, only three representative images are shown in Figure 9 for comparison. The values of average roughness and root-mean-square roughness for the blend films are shown in Table 2. It is clear that the images for both the as-prepared film and the film annealed at $150^{\circ} \mathrm{C}$ look relatively smooth. It is evident that the rougher surface observed in the film annealed at $50^{\circ} \mathrm{C}$ increases the contact area between the active layer and the metal electrode. In addition, as shown in Figure $9 \mathrm{~b}$ and 9e, both PDDTTBT and PCBM domains are uniformly distributed throughout the surface of the film, indicating the nanoscale interpenetrating network has been formed in this blend, which can benefit not only the charge separation but also the charge transport. Hence, the transport rate of charge carriers to the metal electrode is higher and the recombination rate of excitons is reduced. Therefore, the $J-V$ curve for the film annealed at $50^{\circ} \mathrm{C}$ reveals an increase of $J_{\mathrm{sc}}$ to $1.933 \mathrm{~mA} / \mathrm{cm}^{2}$ which is almost twice of that of the film annealed at $150^{\circ} \mathrm{C}$.

Table 2. Surface roughness of PDDTTBT:PCBM blend films obtained from AFM after annealing at different temperatures for $30 \mathrm{~min}$

\begin{tabular}{|l|c|c|c|c|c|c|}
\hline \multicolumn{1}{|c|}{ Annealing temperature } & RT & $\mathbf{5 0}^{\circ} \mathbf{C}$ & $\mathbf{7 5}^{\circ} \mathbf{C}$ & $\mathbf{1 0 0}^{\circ} \mathbf{C}$ & $\mathbf{1 2 5}^{\circ} \mathbf{C}$ & $\mathbf{1 5 0}^{\circ} \mathbf{C}$ \\
\hline Average Roughness [nm] & 1.49 & 1.63 & 1.57 & 1.40 & 1.04 & 0.92 \\
\hline Root mean square [nm] & 2.14 & 2.75 & 2.09 & 1.81 & 1.39 \\
\hline
\end{tabular}



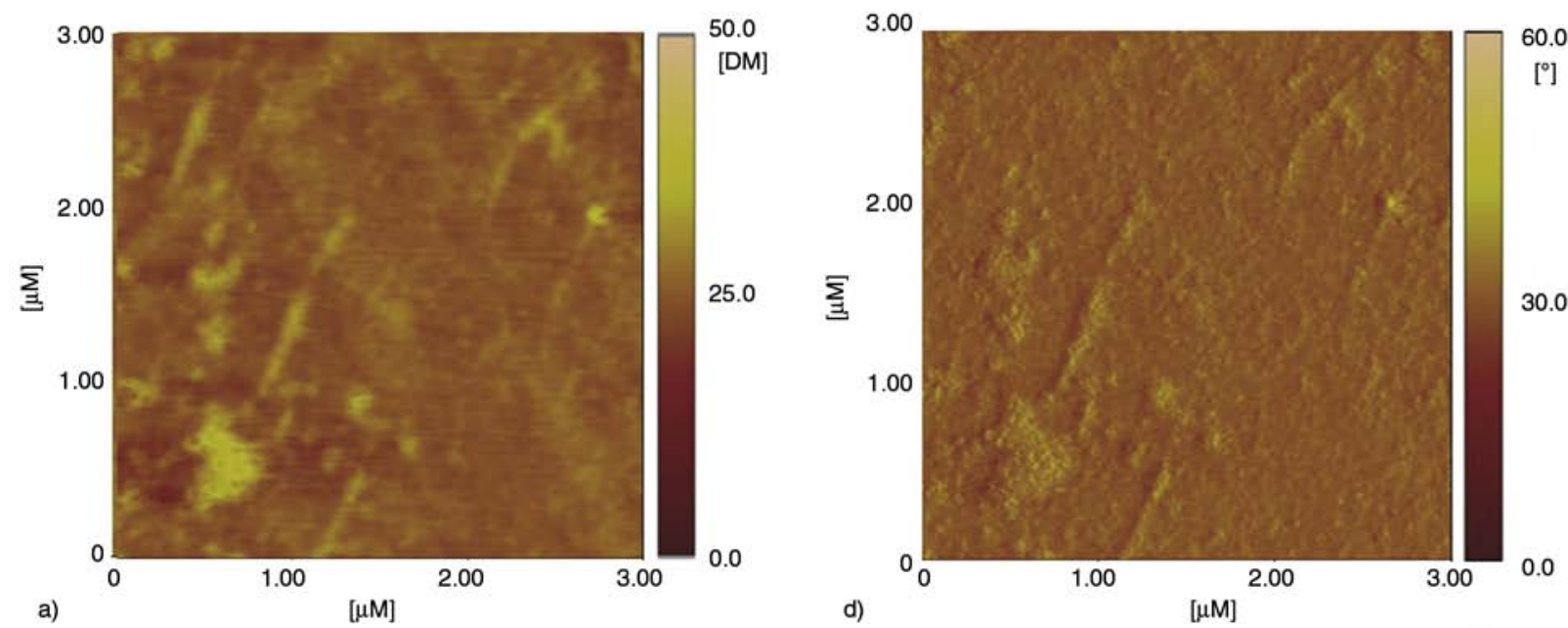

a)

$[\mu \mathrm{M}]$
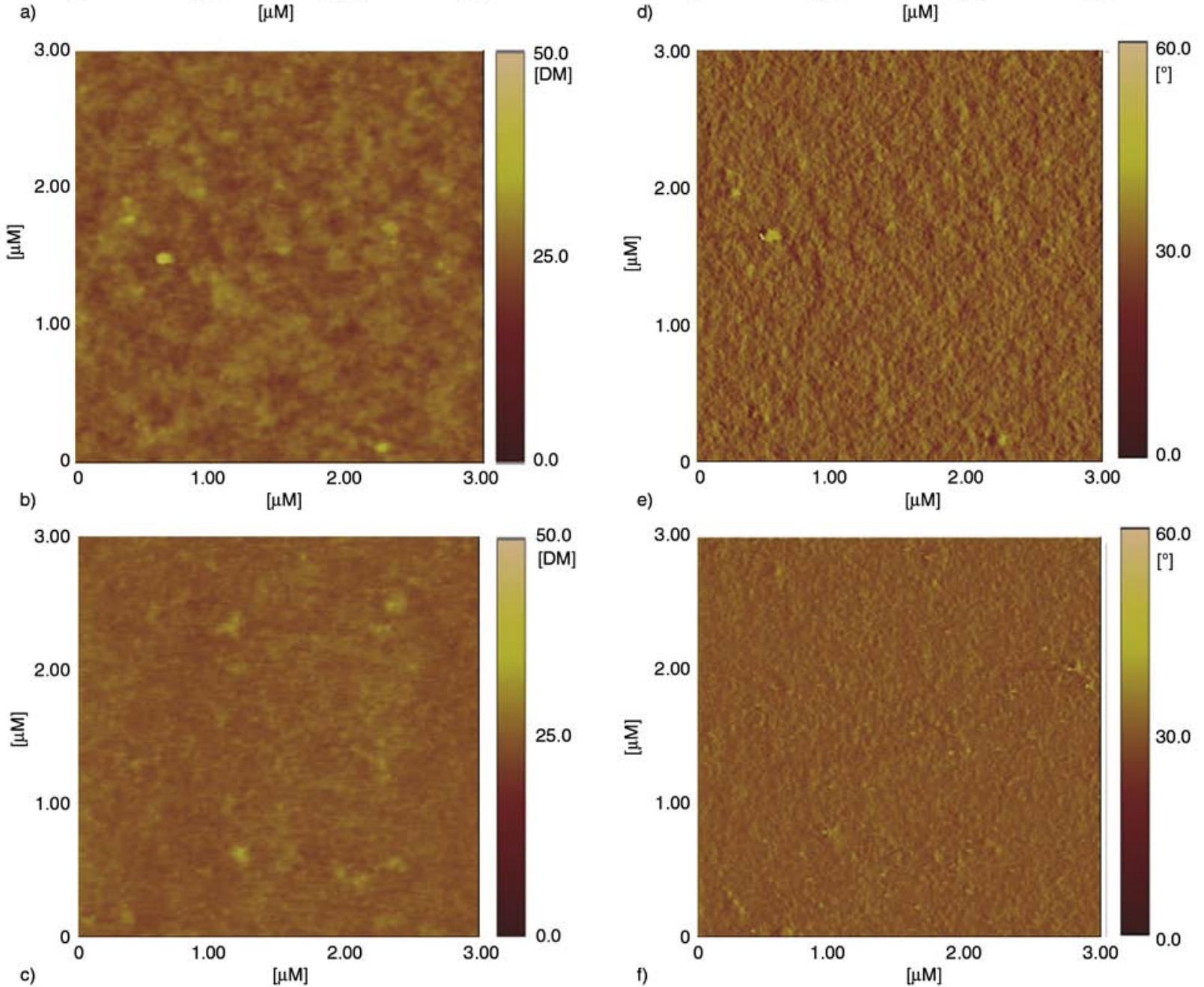

b)

$[\mu \mathrm{M}]$

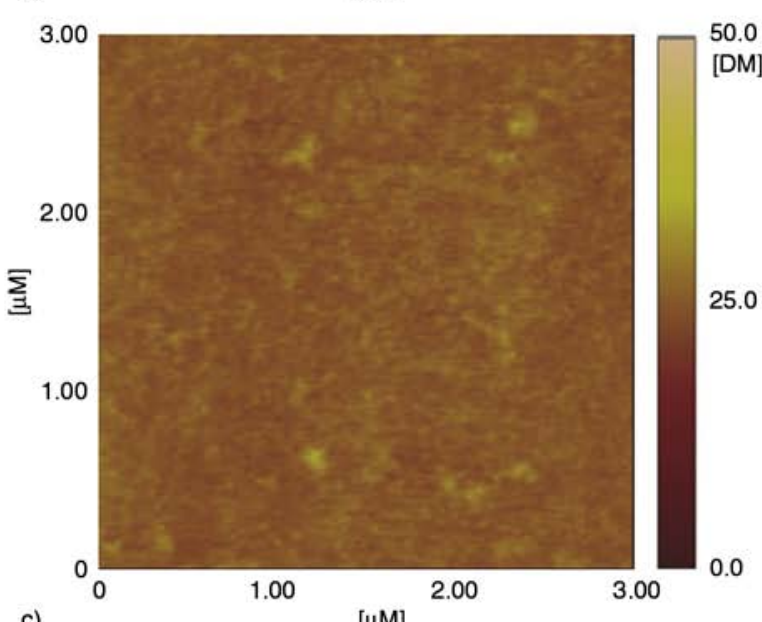

Figure 9. AFM topography images $(3 \mu \mathrm{m} \times 3 \mu \mathrm{m})$ of PDDTTBT:PCBM blend films after annealing at different temperatures for $30 \mathrm{~min} .2 \mathrm{D}$ height image for the blend film (a) unannealed, (b) annealed at $50^{\circ} \mathrm{C}$, (c) annealed at $150^{\circ} \mathrm{C}$. Phase image for the blend film (d) unannealed, (e) annealed at $50^{\circ} \mathrm{C}$, (f) annealed at $150^{\circ} \mathrm{C}$.

\subsection{External quantum efficiency and solar cell performance}

In order to learn more on the recombination mechanisms in the PDDTTBT/ $\mathrm{PC}_{61} \mathrm{BM}$ photoactive layer, EQE measurements with different annealing tem- peratures were performed on the solar cell devices (Figure 10).

As seen in the figure, the EQE spectra of blend films exhibit similar patterns with the optical data. For the untreated sample, two dominant bands pres- 


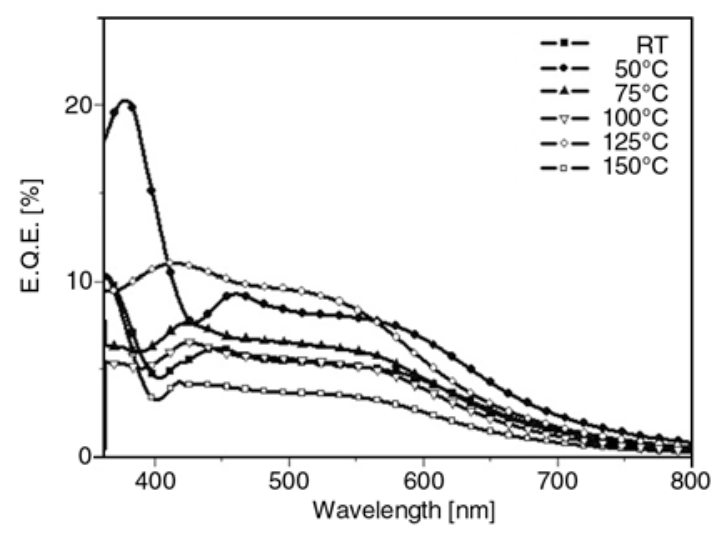

Figure 10. EQE spectra of PDDTTBT:PC61BM blend films after annealing at different temperatures for $30 \mathrm{~min}$

ent at 364 and $446 \mathrm{~nm}$, the obtained EQE is only 10.4 and $6.2 \%$, correspondingly. After thermal treatment for the blend films, the EQE is significantly improved with minor changes in the peak position. Among the EQE spectra taken at different annealing temperatures, the film annealed at $50^{\circ} \mathrm{C}$ almost demonstrates the highest EQE in the most illuminated regions by possessing the EQE of two dominant bands, at 377 and $460 \mathrm{~nm}$, respectively, reaching ca. 20.2 and $9.3 \%$. Consequently, the highest power conversion efficiency $(0.292 \%)$ has been achieved by this blend film. However, the EQE values are still small compared to those of high performance PSCs. The low EQE may be attributed to the high recombination rate of charge carriers in the PDDTTBT/PC61BM blend system, which results in the low photocurrent.

\section{Conclusions}

The D-A type copolymer PDDTTBT based on DDTT and BT units has been synthesized and employed as the donor material in the active layer of BHJ-type polymer solar cells. UV-vis absorption spectra indicated that a low bandgap polymer with a wide absorption band has been obtained. After annealing treatment, an irregular absorption trend in UV-vis spectra was observed due to both donor and acceptor segments possessing pendent side chains. When the blend film was treated at an optimum condition $\left(50^{\circ} \mathrm{C} / 30 \mathrm{~min}\right)$, the $\mathrm{PV}$ cell performance was dramatically improved and the power conversion efficiency of device reached to $0.292 \%$ under white light illumination $\left(100 \mathrm{~mW} / \mathrm{cm}^{2}\right)$. We attribute the higher efficiency to enhanced 3-D interpenetrating networks in the active layer, increase of light absorption, and improved carrier mobility.

\section{Acknowledgements}

We gratefully acknowledge the support of the National Science Council of Republic of China with Grant NSC 992221-E-390-001-MY3.

\section{References}

[1] Inganäs O., Svensson M., Zhang F., Gadisa A., Persson N. K., Wang X., Andersson M. R.: Low bandgap alternating polyfluorene copolymers in plastic photodiodes and solar cells. Applied Physics A: Materials Science and Processing, 79, 31-35 (2004). DOI: $10.1007 / \mathrm{s} 00339-003-2498-5$

[2] Zhang F., Mammo W., Andersson L. M., Admassie S., Andersson M. R., Inganäs O.: Low-bandgap alternating fluorene copolymer/methanofullerene heterojunctions in efficient near-infrared polymer solar cells. Advanced Materials, 18, 2169-2173 (2006). DOI: $10.1002 / \mathrm{adma} .200600124$

[3] Gadisa A., Mammo W., Andersson L. M., Admassie S., Zhang F., Andersson M. R., Inganäs O.: A new donor-acceptor-donor polyfluorene copolymer with balanced electron and hole mobility. Advanced Functional Materials, 17, 3836-3842 (2007). DOI: $10.1002 / \mathrm{adfm} .200700441$

[4] Espinosa N., Hösel M., Angmo D., Krebs F. C.: Solar cells with one-day energy payback for the factories of the future. Energy and Environmental Science, 5, 5117-5132 (2012).

DOI: $10.1039 / \mathrm{C} 1 \mathrm{EE} 02728 \mathrm{~J}$

[5] Zhao G., He Y., Li Y.: 6.5\% efficiency of polymer solar cells based on poly(3-hexylthiophene) and indene-C60 bisadduct by device optimization. Advanced Materials, 22, 4355-4358 (2010).

DOI: $10.1002 /$ adma.201001339

[6] Chang C-Y., Wu C-E., Chen S-Y., Cui C., Cheng Y-J., Hsu C-S., Wang Y-L., Li Y.: Enhanced performance and stability of a polymer solar cell by incorporation of vertically aligned, cross-linked fullerene nanorods. Angewandte Chemie International Edition, 50, 93869390 (2011). DOI: $10.1002 /$ anie. 201103782

[7] Peet J., Kim J. Y., Coates N. E., Ma W. L., Moses D., Heeger A. J., Bazan G. C.: Efficiency enhancement in low-bandgap polymer solar cells by processing with alkane dithiols. Nature Materials, 6, 497-500 (2007). DOI: $10.1038 /$ nmat1928

[8] Wang E. G., Wang L., Lan L. F., Luo C., Zhuang W., Peng J., Cao Y.: High-performance polymer heterojunction solar cells of a polysilafluorene derivative. Applied Physics Letters, 92, 033307/1-033307/3 (2008).

DOI: $10.1063 / 1.2836266$ 
[9] Zhan X., Tan Z., Domercq B., An Z., Zhang X., Barlow S., Li Y., Zhu D., Kippelen B., Marder S. R.: A high-mobility electron-transport polymer with broad absorption and its use in field-effect transistors and allpolymer solar cells. Journal of the American Chemical Society, 129, 7246-7247 (2007).

DOI: $10.1021 /$ ja071760d

[10] Zhou E., Yamakawa S., Tajima K., Yang C., Hashimoto K.: Synthesis and photovoltaic properties of diketopyrrolopyrrole-based donor-acceptor copolymers. Chemistry of Materials, 21, 4055-4061 (2009). DOI: $10.1021 / \mathrm{cm} 901487 \mathrm{f}$

[11] Li Y.: Molecular design of photovoltaic materials for polymer solar cells: Toward suitable electronic energy levels and broad absorption. Accounts of Chemical Research, 45, 723-733 (2012).

DOI: $10.1021 / \operatorname{ar} 2002446$

[12] Hou J., Chen H-Y., Zhang S., Li G., Yang Y.: Synthesis, characterization, and photovoltaic properties of a low band gap polymer based on silole-containing polythiophenes and 2,1,3-benzothiadiazole. Journal of the American Chemical Society, 130, 16144-16145 (2008).

DOI: $10.1021 / \mathrm{ja} 806687 \mathrm{u}$

[13] Liang Y., Wu Y., Feng D., Tsai S-T., Son H-J., Li G., Yu L.: Development of new semiconducting polymers for high performance solar cells. Journal of the American Chemical Society, 131, 56-57 (2009).

DOI: $10.1021 / \mathrm{ja} 808373 \mathrm{p}$

[14] Park S. H., Roy A., Beaupré S., Cho S., Coates N., Moon J. S., Moses D., Leclerc M., Lee K., Heeger A. J.: Bulk heterojunction solar cells with internal quantum efficiency approaching 100\%. Nature Photonics, 3, 297-302 (2009).

DOI: $10.1038 /$ nphoton. 2009.69

[15] Lee K., Sotzing G. A.: Poly(thieno[3,4-b]thiophene). A new stable low band gap conducting polymer. Macromolecules, 34, 5746-5747 (2001).

DOI: $10.1021 / \mathrm{ma} 0106245$

[16] Sotzing G. A., Lee K.: Poly(thieno[3,4-b]thiophene): A p- and n-dopable polythiophene exhibiting high optical transparency in the semiconducting state. Macromolecules, 35, 7281-7286 (2002).

DOI: $10.1021 / \mathrm{ma} 020367 \mathrm{j}$

[17] Lee B., Yavuz M. S., Sotzing G. A.: Poly(thieno[3,4-b] thiophene)s from three symmetrical thieno[3,4- $b]$ thiophene dimers. Macromolecules, 39, 3118-3124 (2006). DOI: $10.1021 / \mathrm{ma} 0526746$

[18] Sun Y. M., Ma Y. Q., Liu Y. Q., Lin Y. Y., Wang Z. Y., Wang Y., Di C. A., Xiao K., Chen X. M., Qiu W. F., Zhang B., Yu G., Hu W. P., Zhu D. B.: High-performance and stable organic thin-film transistors based on fused thiophenes. Advanced Functional Materials, 16, 426-432 (2006).

DOI: $10.1002 / \mathrm{adfm} .200500547$
[19] Sun Y., Liu Y., Ma Y., Di C., Wang Y., Wu W., Yu G., Hu W., Zhu D.: Organic thin-film transistors with high mobilities and low operating voltages based on 5,5'bis-biphenyl-dithieno[3,2-b:2',3'-d]thiophene semiconductor and polymer gate dielectric. Applied Physics Letters. 88, 242113/1-242113/3 (2006). DOI: $10.1063 / 1.2209213$

[20] Li J., Qin F., Li C. M., Bao Q., Chan-Park M. B., Zhang W., Qin J., Ong B. S.: High-performance thinfilm transistors from solution-processed dithienothiophene polymer semiconductor nanoparticles. Chemistry of Materials, 20, 2057-2059 (2008).

DOI: $\underline{10.1021 / \mathrm{cm} 703567 \mathrm{~g}}$

[21] Lu K., Di C., Xi H., Liu Y., Yu G., Qiu W., Zhang H., Gao X., Liu Y., Qi T., Du C., Zhu D.: Novel copolymers incorporating dithieno[3,2-b:2', $\left.3^{\prime}-d\right]$ thiophene moieties for air-stable and high performance organic field-effect transistors. Journal of Materials Chemistry, 18, 3426-3432 (2008).

DOI: $10.1039 / \mathrm{B} 801603 \mathrm{H}$

[22] Millefiorini S., Kozma E., Catellani M., Luzzati S.: Dithienothiophene based polymer as electron donor in plastic solar cells. Thin Solid Films, 516, 7205-7208 (2008).

DOI: $10.1016 /$ j.tsf.2007.12.077

[23] Zhang S., Guo Y., Fan H., Liu Y., Chen H-Y., Yang G., Zhan X., Liu Y., Li Y., Yang Y.: Low bandgap $\pi$-conjugated copolymers based on fused thiophenes and benzothiadiazole: Synthesis and structure-property relationship study. Journal of Polymer Science Part A: Polymer Chemistry, 47, 5498-5508 (2009).

DOI: $10.1002 /$ pola.23601

[24] Chen J., Cao Y.: Development of novel conjugated donor polymers for high-efficiency bulk-heterojunction photovoltaic devices. Accounts of Chemical Research, 42, 1709-1718 (2009)

DOI: $10.1021 / \mathrm{ar} 900061 \mathrm{z}$

[25] Arias A. C., MacKenzie J. D., Stevenson R., Halls J. J. M., Inbasekaran M., Woo E. P., Richards D., Friend R. H.: Photovoltaic performance and morphology of polyfluorene blends: A combined microscopic and photovoltaic investigation. Macromolecules, 34, 6005-6013 (2001).

DOI: $10.1021 / \mathrm{ma} 010240 \mathrm{e}$

[26] Snaith H. J., Greenham N. C., Friend R. H.: The origin of collected charge and open-circuit voltage in blended polyfluorene photovoltaic devices. Advanced Materials, 16, 1640-1645 (2004).

DOI: $10.1002 /$ adma.200305766

[27] Svensson M., Zhang F., Veenstra S. C., Verhees W. J. H., Hummelen J. C., Kroon J. M., Inganäs O., Andersson M. R.: High-performance polymer solar cells of an alternating polyfluorene copolymer and a fullerene derivative. Advanced Materials, 15, 988-991 (2003). DOI: $10.1002 / \mathrm{adma} .200304150$ 
[28] Boudreault P-L. T., Michaud A., Leclerc M.: A new poly(2,7-dibenzosilole) derivative in polymer solar cells. Macromolecular Rapid Communications 28, 2176-2179 (2007).

DOI: $10.1002 /$ marc. 200700470

[29] Blouin N., Michaud A., Leclerc M.: A low-bandgap poly(2,7-carbazole) derivative for use in high-performance solar cells. Advanced Materials, 19, 2295-2300 (2007).

DOI: $10.1002 / \mathrm{adma} .200602496$

[30] Moulé A. J., Tsami A., Bünnagel T. W., Forster M., Kronenberg N. M., Scharber M., Koppe M., Morana M., Brabec C. J., Meerholz K., Scherf U.: Two novel cyclopentadithiophene-based alternating copolymers as potential donor components for high-efficiency bulk-heterojunction-type solar cells. Chemistry of Materials, 20, 4045-4050 (2008).

DOI: $10.1021 / \mathrm{cm} 8006638$

[31] Bundgaard E., Hagemann O., Manceau M., Jørgensen M., Krebs F. C.: Low band gap polymers for roll-toroll coated polymer solar cells. Macromolecules, 43, 8115-8120 (2010).

DOI: $10.1021 / \mathrm{ma} 1015903$

[32] Bundgaard E., Hagemann O., Jørgensen M., Krebs F. C.: Low band gap polymers for roll-to-roll coated organic photovoltaics - Design, synthesis and characterization. Green, 1, 55-64 (2011).

DOI: $10.1515 /$ green.2011.005
[33] Wang T-L., Yeh A-C., Yang C-H., Shieh Y-T., Chen WJ., Ho T-H.: Synthesis and photovoltaic properties of a low bandgap donor-acceptor alternating copolymer with benzothiadiazole unit. Solar Energy Materials and Solar Cells, 95, 3295-3302 (2011). DOI: $10.1016 /$ j.solmat.2011.07.021

[34] He M., Zhang F.: Synthesis and structure of alkyl-substituted fused thiophenes containing up to seven rings. The Journal of Organic Chemistry, 72, 442-451 (2007). DOI: $10.1021 /$ jo061853y

[35] Bouffard J., Swager T. M.: Fluorescent conjugated polymers that incorporate substituted 2,1,3-benzooxadiazole and 2,1,3-benzothiadiazole units. Macromolecules, 41, 5559-5562 (2008). DOI: $10.1021 / \mathrm{ma} 8010679$

[36] Tauc J.: Amorphous and liquid semiconductors. Plenum Press, New York (1974).

[37] Cervini R., Holmes A. B., Moratti S. C., Köhler A., Friend R. H.: Synthesis of new conjugated thiophene polymers. Synthetic Metals, 76, 169-171 (1996). DOI: 10.1016/0379-6779(95)03445-P

[38] Li Y., Xue L., Li H., Li Z., Xu B., Wen S., Tian W.: Energy level and molecular structure engineering of conjugated donor-acceptor copolymers for photovoltaic applications. Macromolecules, 42, 4491-4499 (2009).

DOI: $10.1021 / \mathrm{ma900623p}$ 